\title{
Defect of Cold-sensitive Response in Calmodulin Mutants of Paramecium and the Restoration by Cyclic Nucleotide
}

\author{
Toshihiko Kuriu1,2, Yoshio Oosawa ${ }^{2}$, Yoshiya Watanabe ${ }^{3}$, and Yasuo Nakaoka ${ }^{1, *}$ \\ ${ }^{1}$ Department of Biophysical Engineering, Faculty of Engineering Science, Osaka University, Toyonaka, Osaka \\ 560, Japan, 2 International Institute for Advanced Research, Matsushita Electric Industrial Co., Ltd. 3-4 \\ Hikaridai, Seika, Kyoto 619-02, Japan, and ${ }^{3}$ Department of Medical Biology, Kochi Medical School, Okohcho, \\ Nankoku, Kochi 783, Japan
}

Key words: cold-sensory response/calmodulin/cyclic nucleotides/mutant/Paramecium

\begin{abstract}
Wild type and calmodulin mutants (cam) of Paramecium tetraurelia were examined for cold-sensitive responses. Among mutants tested, $\mathrm{cam}^{12}$ and $\mathrm{cam}^{13}$ mutants, which have substitutions in N-terminal lobe of calmodulin molecule, reduced both responses in the swimming and the membrane potential. Under voltage clamp conditions, the cooling stimulus to the wild type cell induced a transient inward current whose amplitude increased with the rate of temperature drop. The cam $^{12}$ cell did not induce inward currents in response to cooling with a rate slower than $-0.4^{\circ} \mathrm{C} / \mathrm{s}$. The reduced current response of cam $^{12}$ mutant was restored by an external application of a phosphodiesterase inhibitor, theophylline. Also, an intracellular injection of hydrolysis-resistant cyclic nucleotides, either 8-bromoadenosine $3^{\prime}, 5^{\prime}$-cyclic monophosphate (8-Br-cAMP) or 8-bromoguanosine 3,5'-cyclic monophosphate (8-Br-cGMP), restored the current response. Such restoration was accompanied by shifts of the resting potential to hyperpolarized levels and by an increase in the membrane conductance. The results suggest the possibility that calmodulin and cyclic nucleotide regulate $\mathrm{K}^{+}$channels responsive to the cooling stimulus.
\end{abstract}

Thermosensory receptors are ubiquitous in many organisms, and they are specified as warm and cold receptors. However, the mechanisms of thermosensory-transduction are not well understood. The ciliated protozoan, Paramecium has warm and cold receptors. Warming above the temperature to which the cells have been adapted, and cooling below this temperature induces transient increases in the frequency of directional changes in the swimming behavior $(4,18)$. Both warming and cooling stimuli induce slow transient depolarizations of the membrane potential, which trigger spikelike depolarizations and in turn cause the directional changes in the swimming. It has been shown that the depolarization induced by warming is accompanied by an increase in the membrane conductance for $\mathrm{Ca}^{2+}(5,16$, 26 ), and the depolarization induced by cooling is accompanied primarily by a decrease in the membrane conductance for $\mathrm{K}^{+}(7,16)$.

Among many behavioral mutants of Paramecium, some have substitutions of amino acid residues in the calmodulin molecule $(9,11)$. There are two groups; mutants having substitutions in the C-terminal lobe of cal-

\footnotetext{
* To whom correspondence should be addressed.

Tel: +81-6-850-6543, Fax: +81-6-850-6557

E-mail: nakaoka@bpe.es.osaka-u.ac.jp
}

modulin molecule carry defects in the interaction of calmodulin with a $\mathrm{Ca}^{2+}$-dependent $\mathrm{K}^{+}$channel. Mutants having substitutions in the $\mathrm{N}$-terminal lobe prevent the interaction of calmodulin with a $\mathrm{Ca}^{2+}$-dependent $\mathrm{Na}^{+}$ channel. The latter is directly activated by the binding of $\mathrm{Ca}^{2+}$-calmodulin $(23,24)$. The role of calmodulin in exocytosis has also been defined through analyses of these calmodulin mutants (8).

In the present study, we compare the cold-sensitive responses between the wild type and the calmodulin mutants. The results show that cam $^{12}$ and cam $^{13}$ mutants are defective in the cold-sensitive response. In addition, the defect of $\mathrm{cam}^{12}$ is restored either by an external application of theophylline or by an intracellular injection of cyclic nucleotides. These results suggest that calmodulin and cyclic nucleotides are included in the cold-sensory transduction chain.

\section{MATERIALS AND METHODS}

Cell culture. Paramecium tetraurelia, wild type (stock 51 s) and the following calmodulin mutants supplied by Dr. C. Kung (Madison, WI, USA) were used; Pantophobiac type mutants that show a strong backward swimming in $\mathrm{Na}^{+}$solution were $\mathrm{cam}^{1}$ and $\mathrm{cam}^{2}$. Fast-2 type mutants that show no backward swimming in $\mathrm{Na}^{+}$solution were $\mathrm{cam}^{12}$ and $\mathrm{cam}^{13}$ (9). 
Wild and mutant cells were cultured in hay infusion inoculated with Klebsiella pneumoniae. Culture temperature was kept constant at $25^{\circ} \mathrm{C}$ by incubating culture vessels in a water bath. Stationary cells were collected by low speed centrifugation and suspended in a standard solution. The cell suspension was left for $1 \mathrm{~h}$ or more at $25^{\circ} \mathrm{C}$ prior to the experiments.

Solutions. The standard solution contained $1 \mathrm{mM} \mathrm{CaCl}_{2}$, $0.5 \mathrm{mM} \mathrm{MgCl} 2,4 \mathrm{mM} \mathrm{KCl}, 1 \mathrm{mM}$ HEPES (pH 7.2, adjusted with Tris $^{+}$). In some cases of current measurement, $10 \mathrm{mM}$ $\mathrm{NaCl}$ was added to the standard solution or $\mathrm{MgCl}_{2}$ was omitted from the standard solution. Theophylline (Wako, Japan) was added to the standard solution in a final concentration of $5 \mathrm{mM}$. The solution for intracellular injections contained either $1 \mathrm{mM}$ 8-bromo-cAMP or $1 \mathrm{mM}$ 8-bromo-cGMP and 2 mM HEPES-Tris (pH 7.2, adjusted with $\mathrm{KOH}$ ). Chemicals used for the microinjection were obtained from Sigma.

Behavioral assays. Cells suspended in the standard solution were placed in a glass vessel whose temperature was controlled by water flow beneath it (18). An abrupt change of the temperature was achieved by switching a valve connected to outlets of two different temperature-regulating units. The temperature of the cell suspension was measured with a thermistor placed in the vessel. The time constant of the thermistor was $0.4 \mathrm{~s}$. Swimming behavior of cells was monitored with a video camera mounted just above the vessel and was recorded by a video-tape recorder. Swimming tracks of $1 \mathrm{~s}$ duration were obtained from the video record by using an image processor (Image Sigma-2, Avionics, Japan). Among the swimming tracks of 70-150 cells, those that changed the swimming direction were counted and this fraction was taken as frequency of directional changes.

Intracellular recording. Membrane potential and membrane current were measured by the methods described previously (15). Microelectrodes used for the current clamp contained $0.1 \mathrm{M} \mathrm{KCl}$ and the tip resistances were $150-200 \mathrm{M} \Omega$. Voltage clamp electrodes contained $1 \mathrm{M} \mathrm{KCl}$ and the resistances were about $50 \mathrm{M} \Omega$. For measurements in the absence of depolarizing spikes, cells were deciliated by incubation in the standard solution containing 5\% ethanol for $0.5-1 \mathrm{~min}$ and then returned to the standard solution (7). Intracellular measurements of the deciliated cells were made in a vessel mounted on an inverted microscope. The temperature of the vessel was controlled by a water flow beneath it, and was changed by switching the water flow. The temperature was measured with a thermo-couple placed near the cell. The time constant of the thermo-couple was $0.1 \mathrm{~s}$.

Microinjection. The arrangement for pressure injections was a modification of a method described by Oosawa and Yamagishi (21). The tip diameter of the microcapillary used for injection was about $1 \mu \mathrm{m}$. An air pressure pulse of 10-30 psi $\times 0.1-0.5 \mathrm{~s}$ was applied for the injection (Picosprizer, General Valve, USA). Injected volumes were 10-20 pl.

Assay of cyclic nucleotides. The cells were washed with the standard solution and concentrated to $5 \times 10^{4}$ cells $/ \mathrm{ml}$. After standing at $25^{\circ} \mathrm{C}$ for about $10 \mathrm{~min}$, the cells were dis- rupted by addition of $\mathrm{HCl}$ to a final concentration of $0.1 \mathrm{M}$, and then neutralized by the addition of $\mathrm{KOH}$. Cell debris were removed by centrifugation $\left(10^{4} \mathrm{~g} \times 10 \mathrm{~min}\right)$ and the supernatant was used for the measurements of cAMP and cGMP with a radio-immuno assay kit (Yamasa, Japan). For estimation of intracellular concentrations of cyclic nucleotides, the cell volume was calculated to be $100 \mathrm{pl}$ from the microscopic observation of the cell size.

\section{RESULTS}

Swimming responses to cooling. When the temperature of cell vessel started to drop from $25^{\circ} \mathrm{C}$ with an initial rate of cooling, $-0.13^{\circ} \mathrm{C} / \mathrm{s}$, wild-type $P$. tetraurelia rapidly increased the frequency of directional changes in the swimming, attained a peak value after 10-20 s, and decreased gradually thereafter (Fig. 1). Calmodulin mutants, cam $^{I}$ and cam $^{2}$ increased transiently the frequency of directional changes, which were similar to the wild type cell. On the other hand, $\operatorname{cam}^{12}$ and $\operatorname{cam}^{13} \mathrm{mu}-$ tants showed almost no or only a small increase in the frequency of directional changes upon cooling.

Membrane potential responses to cooling. The resting potentials of cells used in this study (wild type, $c^{a m^{1}}, \mathrm{cam}^{2}, \mathrm{cam}^{12}, \mathrm{cam}^{13}$ mutants) were in the range from -22 to $-26 \mathrm{mV}$ at $25^{\circ} \mathrm{C}$. When the temperature of experimental vessel was reduced from $25^{\circ} \mathrm{C}$, with an initial rate of cooling, $-0.13^{\circ} \mathrm{C} / \mathrm{s}$, wild type cells and $\mathrm{cam}^{1}$ and $\mathrm{cam}^{2}$ mutants showed transient depolarizations (Fig. 2). The amplitudes of the depolarization (mean \pm s.d.) were $4.0 \pm 1.5 \mathrm{mV}(\mathrm{n}=15), 5.0 \pm 2.8 \mathrm{mV}$ $(\mathrm{n}=5), 3.2 \pm 0.3 \mathrm{mV}(\mathrm{n}=7)$ for wild type cells, $\mathrm{cam}^{1}$ and $\mathrm{cam}^{2}$ mutants, respectively. On the other hand, depolarizations in $\mathrm{cam}^{12}$ and $\mathrm{cam}^{13}$ mutants were not distinguished from fluctuations of the resting potential (Fig. 2). Based on these results, we hereafter compared the cold-sensitive response between wild type cell and cam $^{12}$ mutant.

Voltage dependence of cold-sensitive response. Under the voltage clamp, cooling stimuli with an initial rate of cooling, $-0.34^{\circ} \mathrm{C} / \mathrm{s}$, were applied. In the wildtype cells, a transient inward current occurred that peaked 10-20 s after the start of cooling. However, the same rate of cooling stimulation applied to the cam $^{12}$ cells induced almost no inward currents (Fig. 3A). These current responses were tested at various membrane potentials. The current amplitudes of the wild type cell increased with positive shifts of the potential, and decreased with negative shifts. Reversal of the current direction occurred at about $-40 \mathrm{mV}$ (Fig. 3B). On the other hand, $\operatorname{cam}^{12}$ showed no current responses, irrespective of the membrane potential.

Because cam $^{12}$ mutant lacks both $\mathrm{Ca}^{2+}$-dependent $\mathrm{Na}^{+}$channels and $\mathrm{Ca}^{2+}$-dependent $\mathrm{Mg}^{2+}$ channels $(9$, $10)$, the current response upon cooling of the wild type 

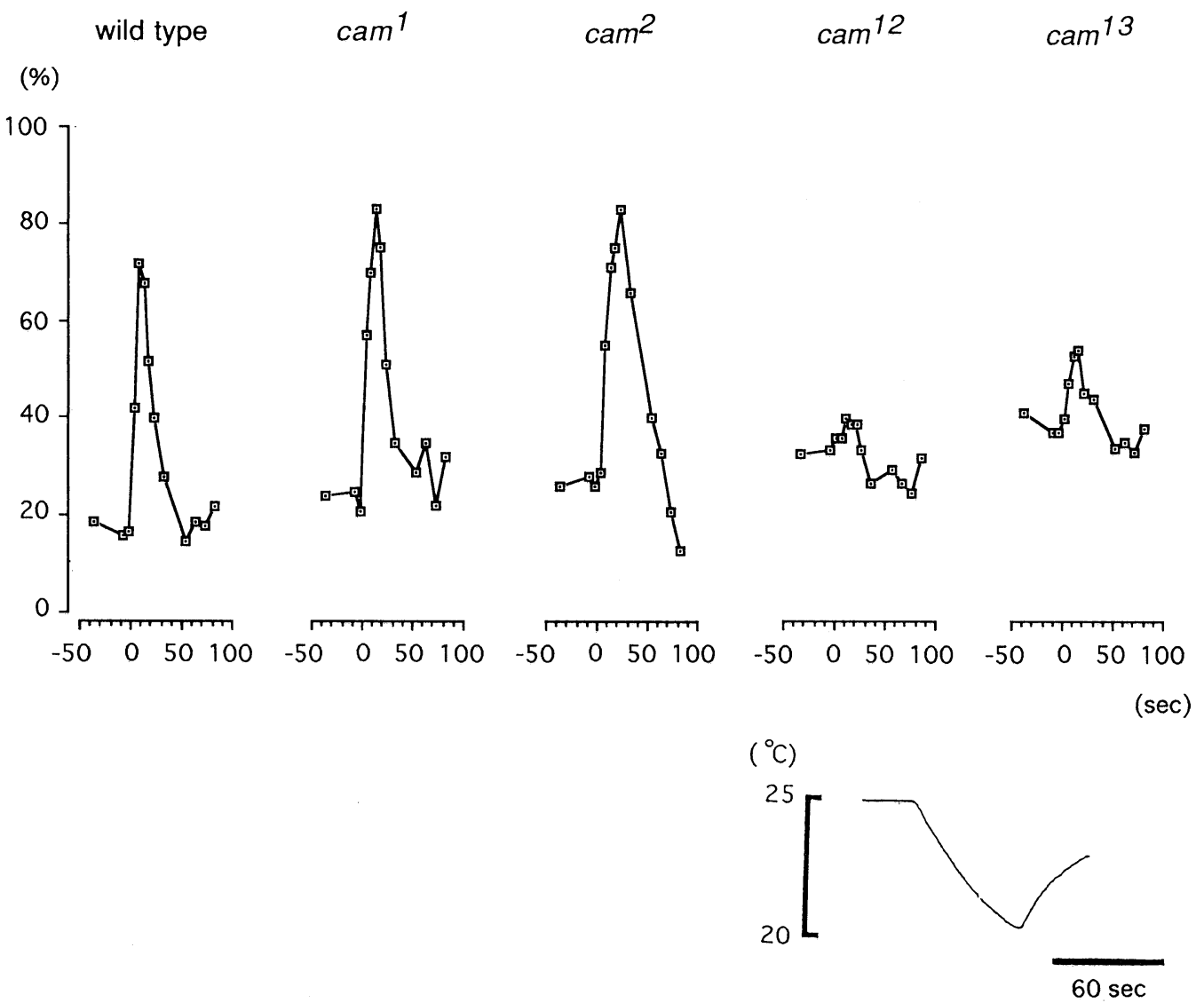

Fig. 1. Behavioral response to cooling stimuli. Wild type and cam mutant cells were placed in the vessel of $25^{\circ} \mathrm{C}$, and then subjected to the initial rate of cooling, $-0.13^{\circ} \mathrm{C} / \mathrm{s}$ at $0 \mathrm{~s}$ on the abscissa. The swimming responses are expressed by $\%$ of cells showing directional changes in the swimming (see Materials and Methods). The bottom trace gives the temperature change in the vessel.

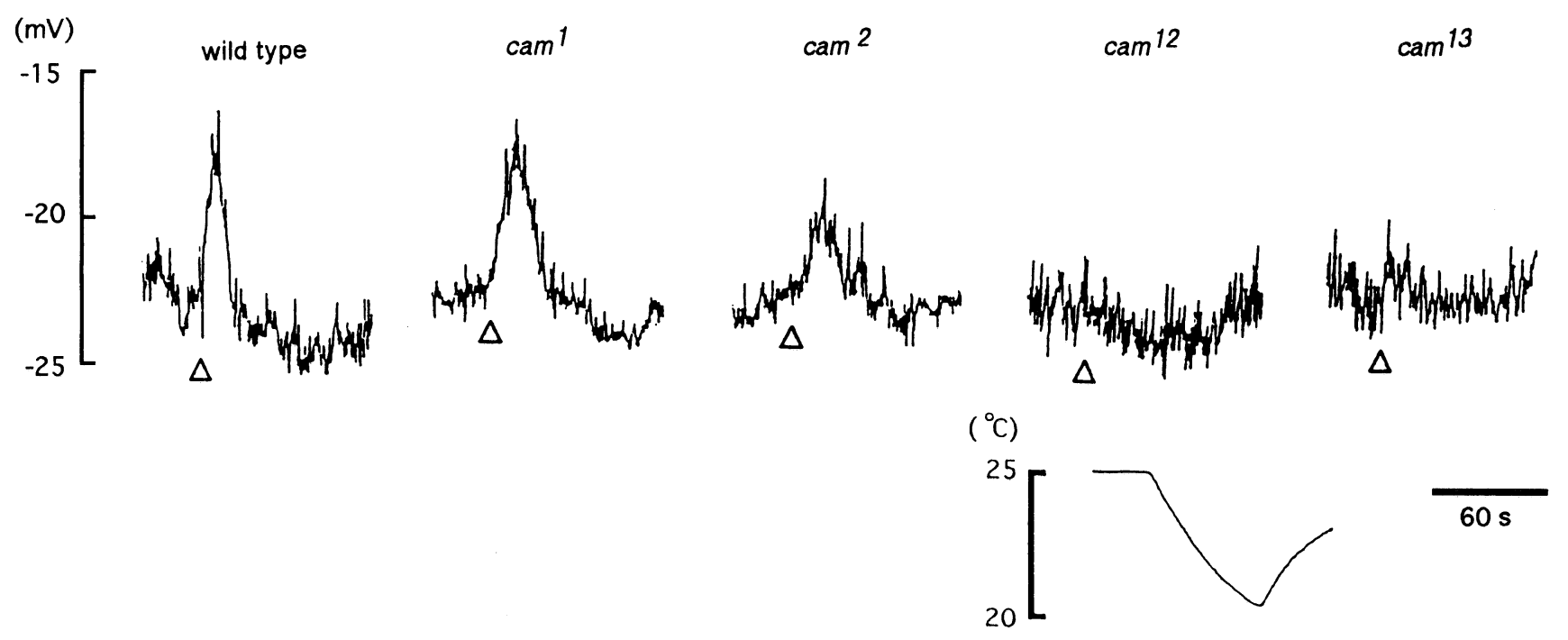

Fig. 2. Membrane potential responses to cooling stimuli. Deciliated cells were used for all measurements of the electrophysiology. Wild type and cam mutant cells were bathed in the standard solution controlled at $25^{\circ} \mathrm{C}$ and impaled with microelectrodes to measure the membrane potential. The cooling stimuli were started at time indicated open triangles. The initial rate of cooling was $-0.13^{\circ} \mathrm{C} / \mathrm{s}$. Bottom trace shows temperature change in the vessel. 


\section{wild type $\quad$ cam $^{12}$}

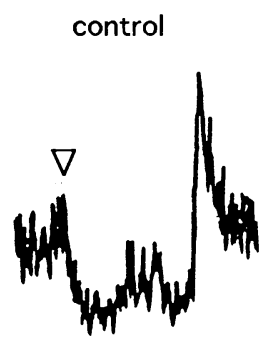

$+4 \mathrm{mV}$

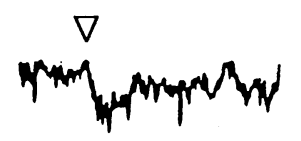

$-18 m V$

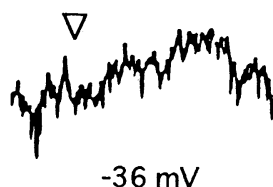

$-36 m V$
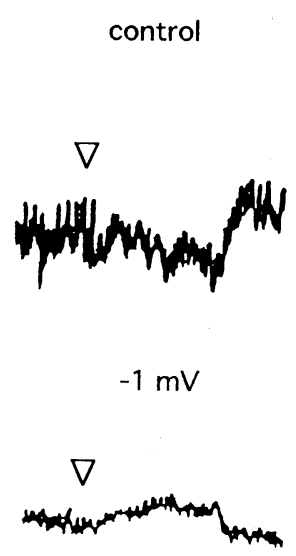

$-21 \mathrm{mV}$

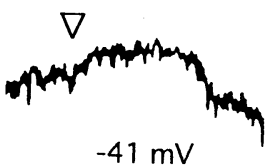

$\left({ }^{\circ} \mathrm{C}\right)$

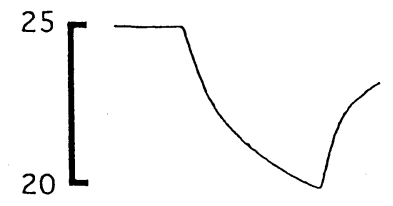

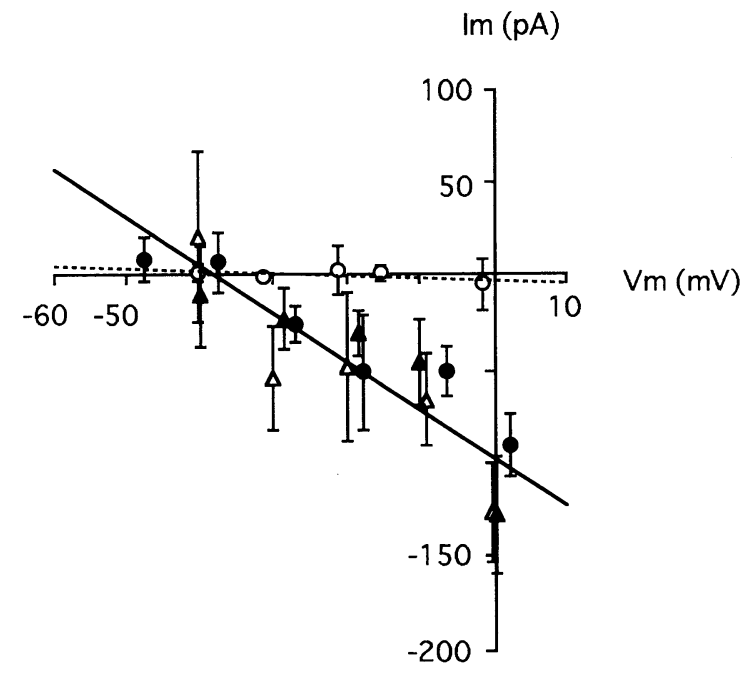

3B
Fig. 3. Current responses to cooling stimuli. Wild type and cam $^{12}$ mutant cells were voltage clamped at various potentials in the experimental solution at $25^{\circ} \mathrm{C}$, and cooling stimuli were applied. The initial rate of cooling was $-0.34^{\circ} \mathrm{C} / \mathrm{s}$. (A) Current responses of wild type and $\mathrm{cam}^{12}$ mutant cells. The membrane potential was clamped at various levels indicated at the left side of the current traces, and the cooling was started at open triangles. Bottom trace gives temperature change in the vessel. (B) Voltage dependence of the current response. From the current records at various potentials, amplitudes of the maximal current changes at $10 \mathrm{~s}$ after the start of cooling were obtained. The amplitudes of wild type (filled circle, open and closed triangles) and $\mathrm{cam}^{12}$ mutant (open circle) cells are plotted as a function of the membrane potential. Open triangles are amplitudes in the $10 \mathrm{mM} \mathrm{NaCl}$ solution. Closed triangles are amplitudes in the solution without $\mathrm{MgCl}_{2}$. Each point represents the means \pm SD of 3-7 cells. cells might include $\mathrm{Na}^{+}$or $\mathrm{Mg}^{2+}$ current. So, the current response of the wild type cell was therefore tested in the medium containing $10 \mathrm{mM} \mathrm{NaCl}$ or in the medium without $\mathrm{MgCl}_{2}$. However, neither the amplitude nor the reversal potential of the current responses changed from those seen in the standard solution (Fig. 3B).

Effect of cooling rate on the current response. When the initial rate of cooling from $25^{\circ} \mathrm{C}$ was slower than $-0.34^{\circ} \mathrm{C} / \mathrm{s}$, the wild cell responded with an inward current, whereas cam $^{12}$ did not show such current (Fig. 4A). When the rate of cooling was higher than $-0.46^{\circ} \mathrm{C} / \mathrm{s}, \operatorname{cam}^{12}$ mutant began to display a current response whose amplitude was smaller than that of the wild type (Fig. 4A, B). Therefore, cam $^{12}$ mutant cells retained an attenuated sensitivity to the cooling stimulus as compared to the wild-type cell.

Effects of theophylline and cyclic nucleotide-injection. In an attempt to restore the cooling sensitivity of cam $^{12}$ mutant cells, we found that the phosphodiesterase inhibitor theophylline restored the sensitivity. For this examination, cam $^{12}$ cells were voltage clamped and stimulated at a cooling rate of $-0.34^{\circ} \mathrm{C} / \mathrm{s}$ that induced no current responses in cam $^{12}$ cell. When $5 \mathrm{mM}$ theophylline was added to the experimental medium, cam $^{12}$ mutant cells displayed a current response (Fig. 5A).

In order to know whether such an effect of theophyl- 

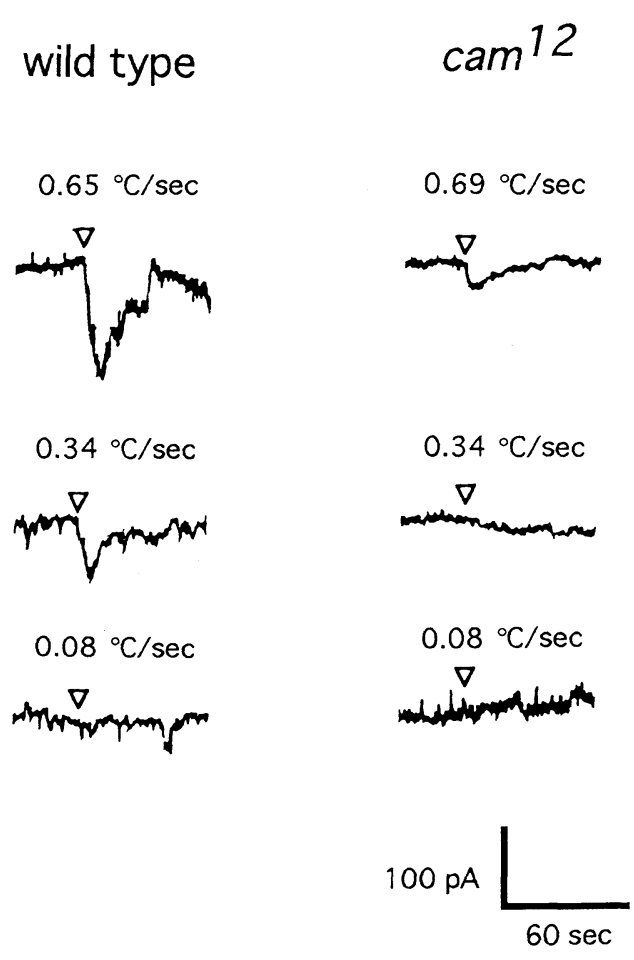

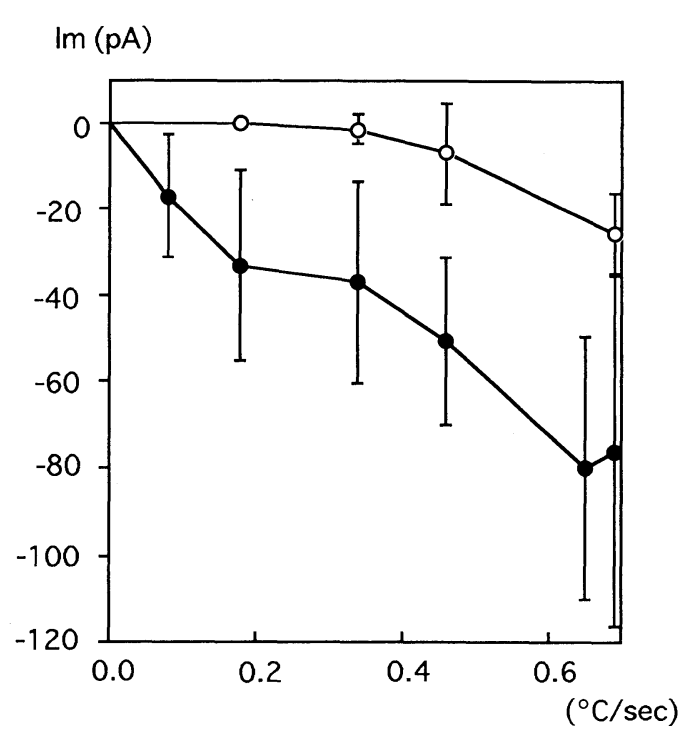

4B

4A

Fig. 4. Effect of cooling rate on the current responses. Wild type and cam ${ }^{I 2}$ cells were voltage clamped at $-25 \mathrm{mV}$ in the standard solution of $25^{\circ} \mathrm{C}$, and various rates of cooling stimuli were applied. (A) Current responses induced by various rates of cooling. Initial cooling rates and the start of cooling (open triangle) are shown on top of the traces. (B) Relationship between the cooling rate and the amplitude of current response. From the current responses induced by various cooling rates, amplitudes of the maximal current changes at $10 \mathrm{~s}$ after the start of cooling were obtained. The amplitudes of wild type (closed circle) and $\mathrm{cam}^{12}$ mutant (open circle) cells are plotted as a function of the cooling rate. Data are means \pm SD of $4-8$ cells.

line was related to an increase in the intracellular concentration of cyclic nucleotides, cAMP and cGMP were intracellularly injected into $\mathrm{cam}^{12}$ cells. Injection of either cAMP or cGMP induced the inward current response to the cooling at $-0.34^{\circ} \mathrm{C} / \mathrm{s}$, but the effect disappeared within a few minutes after the injection. Therefore, instead of cAMP and cGMP, we used hydrolysisresistant analogs, 8-Br-cAMP and 8-Br-cGMP. After injection of either 8-Br-cAMP or 8-Br-cGMP, cam $^{12}$ mutant cells regained the inward current responses (Fig. $5 \mathrm{~A})$.

Amplitudes of the current responses at various membrane potentials were then compared under those conditions which caused current responses upon cooling at $-0.34^{\circ} \mathrm{C} / \mathrm{s}$ (Fig. 5B). The current amplitudes elicited after addition of theophylline were slightly larger than those restored by the injections of 8-Br-cAMP and 8Br-cGMP, and amplitudes caused by both 8-Br-cAMP and 8-Br-cGMP were almost similar to that of the wild type cell. All these current responses were reversed at about $-40 \mathrm{mV}$. The results suggest that addition of theophylline or cyclic nucleotide-injection can restore the cooling sensitivity of $\mathrm{cam}^{12}$ mutant.
Membrane potentials and membrane resistances. Under the conditions that restored the current response of cam $^{12}$ mutant, the resting potential and the membrane resistance changed from the control condition (Table I). The resting potential of the $\mathrm{cam}^{12}$ slightly depolarized from that of wild type, and the membrane resistance of $\mathrm{cam}^{12}$ mutant was 1.2 times larger than that of the wild type. When the cam $^{12}$ mutant was transferred into the medium containing theophylline or injected with 8-Br-cAMP or 8-Br-cGMP, the membrane potentials shifted to hyperpolarized levels and the membrane resistances decreased from those of the original condition. These changes agree with previous reports on the effects of cyclic nucleotides and analogs on Paramecium $(3,17)$.

Contents of $c A M P$ and $c G M P$. Because the intracellular injections of cyclic nucleotide analogs restored the cooling-sensitive response of $\mathrm{cam}^{12}$ mutant, cyclic nucleotide levels of $\mathrm{cam}^{12}$ cell might be reduced from the level of wild-type cell. So, we compared the contents of cyclic nucleotides between wild type and $\mathrm{cam}^{12}$ mutant cells. Contents of cAMP (mean \pm s.d.) were $16.1 \pm 2.0$ pmoles $/ 10^{5}$ cells $(n=6)$ and $15.9 \pm 2.0$ pmoles $/ 10^{5}$ cells 


\section{$\operatorname{cam}^{12}$}

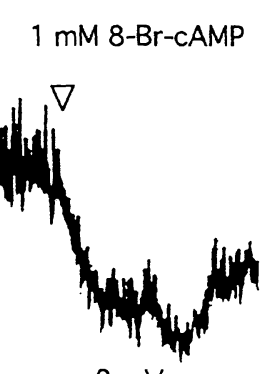

$-8 \mathrm{mV}$

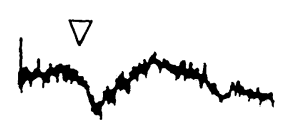

$-20 m V$

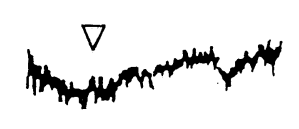

$-46 m V$
$1 \mathrm{mM} 8-\mathrm{Br}-\mathrm{cGMP}$

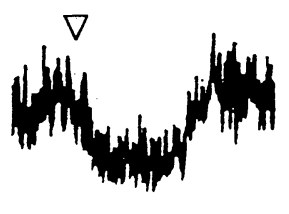

$-10 \mathrm{mV}$

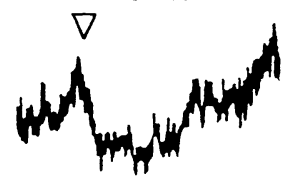

$-21 \mathrm{mV}$

$\nabla$

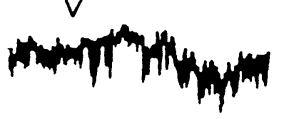

$-43 \mathrm{mV}$
$5 \mathrm{mM}$ theophylline
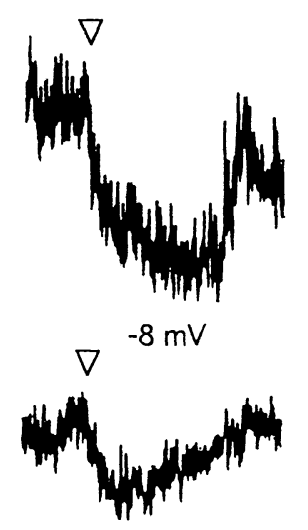

$-20 \mathrm{mV}$

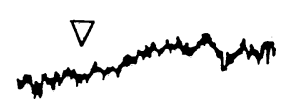

$-40 m V$

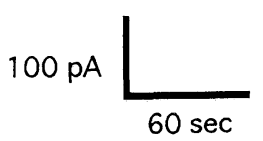

$\left({ }^{\circ} \mathrm{C}\right)$

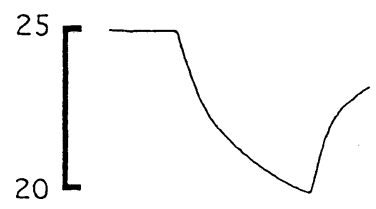

$\operatorname{lm}(\mathrm{pA})$

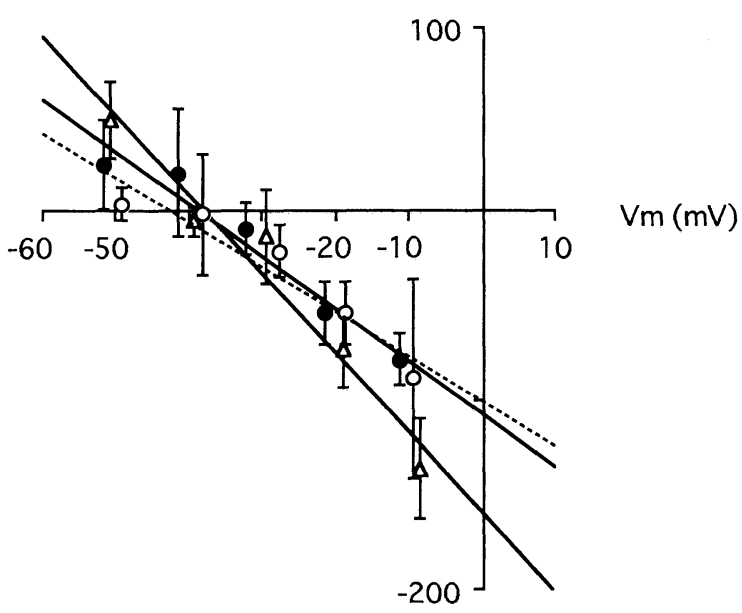

5B

Fig. 5. Effects of theophylline, 8-Br-cAMP and 8-BrcGMP on the cold-sensitive current of cam $^{12}$ mutant. Deciliated $\mathrm{cam}^{12}$ cells were voltage-clamped at various potentials in a solution of $25^{\circ} \mathrm{C}$, and cooling stimuli at $-0.34^{\circ} \mathrm{C} / \mathrm{s}$ were applied. (A) Current responses at various potentials. For the test of theophylline, $5 \mathrm{mM}$ theophylline was added into the external standard solution. For the tests of 8-Br-cAMP and 8-Br-cGMP, these chemicals were injected into the cell. Membrane potentials are indicated beneath the current traces. The start of cooling is indicated by open triangles. The bottom trace shows temperature change in the vessel. (B) Voltage dependence of the current responses restored by theophylline, 8-Br-cAMP and 8-Br-cGMP. Following treatment of these chemicals, current responses at various membrane potentials were recorded. Amplitudes of the maximal current changes at $10 \mathrm{~s}$ after the start of cooling were obtained from records following treatment with theophylline (open triangle), 8-BrcAMP (open circle) or 8-Br-cGMP (closed circle). Points are means \pm SD from 3-5 cells.

5A

Table I. Resting potentials and membrane Resistances in Wild type and cam ${ }^{12}$ mutant of Paramecium.

\begin{tabular}{lllll}
\hline Cell type & Treatment & $\mathrm{V}_{\text {rest }}(\mathrm{mV})$ & $\mathrm{R}_{\mathrm{m}}(\mathrm{M} \Omega)^{\star}$ & $\mathrm{n}$ \\
\hline wild & Control & $-26.1 \pm 4.0$ & $71.5 \pm 11.8$ & 30 \\
cam $^{12}$ & Control & $-24.9 \pm 4.9$ & $85.8 \pm 15.9$ & 24 \\
cam $^{12}$ & Theophylline* & $-28.9 \pm 6.4$ & $69.6 \pm 14.9$ & 14 \\
cam $^{12}$ & 8-Br-cGMP\# & $-31.6 \pm 5.0$ & $58.0 \pm 9.1$ & 5 \\
cam $^{12}$ & 8-Br-cAMP\# & $-32.2 \pm 6.0$ & $58.0 \pm 10.4$ & 5
\end{tabular}

Values represent mean $\pm \mathrm{SD}$ of $\mathrm{n}$ cells. Most measurements except theophylline treatment were done in the standard solution at $25^{\circ} \mathrm{C}$.

$\star$ : input resistance obtained by application of current pulse $(-0.1 \mathrm{nA} \times 0.5 \mathrm{~s})$ at the resting potential. *: $5 \mathrm{mM}$ theophylline was added into the standard solution. \#: injected into the cell. 
$(\mathrm{n}=5)$ for wild type and cam $^{12}$ mutant cells, respectively. Contents of cGMP (mean \pm s.d.) were $8.4 \pm 0.8$ pmoles $/ 10^{5}$ cells $(n=3)$ and $7.6 \pm 0.5$ pmoles $/ 10^{5}$ cells $(\mathrm{n}=2)$ for wild type and cam $^{12}$ mutant cells, respectively. These measurements suggest that cAMP and cGMP concentrations of the $\mathrm{cam}^{12}$ mutant are similar to those of wild type cells.

\section{DISCUSSION}

Cold-sensitive responses of the wild type and calmodulin mutants. Comparisons of the cold-sensitive responses between wild type and calmodulin mutants show that these responses are reduced in $\mathrm{cam}^{12}$ and cam $^{13}$ mutants. Cam $^{12}$ mutant cells display the inward current response only when the rate of cooling was faster than $-0.46^{\circ} \mathrm{C} / \mathrm{s}$, whereas wild type cells responds to cooling already at rates as low as $-0.08^{\circ} \mathrm{C} / \mathrm{s}$ (Fig. 4B). The present results suggest that calmodulin is involved in the sensitivity to the cooling stimulus.

It has been shown that $\mathrm{cam}^{I}$ and $\mathrm{cam}^{2}$ mutants have a defect in generating the $\mathrm{Ca}^{2+}$-dependent $\mathrm{K}^{+}$current, and that $\mathrm{cam}^{12}$ and $\mathrm{cam}^{13}$ mutants can generate neither the $\mathrm{Ca}^{2+}$-dependent $\mathrm{Na}^{+}$current or the $\mathrm{Ca}^{2+}$-dependent $\mathrm{Mg}^{2+}$ current $(9,10,22)$. These findings suggest that, firstly, the $\mathrm{Ca}^{2+}$-dependent $\mathrm{K}^{+}$current is unlikely to be involved in the inward current response upon cooling, because $\mathrm{cam}^{1}$ and $\mathrm{cam}^{2}$ mutants responded to the cooling stimulus as well as wild type cells. Secondly, the assumption that the reduced sensitivity of $\mathrm{cam}^{12} \mathrm{might}$ be related to the defect in the inward $\mathrm{Na}^{+}$current or the $\mathrm{Ca}^{2+}$-dependent $\mathrm{Mg}^{2+}$ current is not realistic, because an external addition of $\mathrm{Na}^{+}$or removal of external $\mathrm{Mg}^{2+}$ changed neither the amplitude of current response nor the reversal potential of the cooling-sensitive current.

Previous reports have shown that the transient depolarization upon cooling is accompanied primarily by a decrease in the membrane conductance for $\mathrm{K}^{+}$at the resting potential $(7,16)$. In the present study, the amplitudes of the current responses were decreased by hyperpolarization and reversed at approximately -40 $\mathrm{mV}$, which is almost the equilibrium potential for $\mathrm{K}^{+}$ $(19,20)$. Therefore, the present results also suggest that the cooling stimulus induces transient changes in the membrane conductance for $\mathrm{K}^{+}$. Comparison of the membrane resistances at the resting state, shows that cam $^{12}$ mutant input resistance is 1.2 times larger than that of the wild type (Table I). The reduced cooling sensitivity of $\mathrm{cam}^{12}$ mutant might be related to this increase in membrane input resistance. Because most of the resting conductance is based on open $\mathrm{K}^{+}$channels (13), a reduction of the conductance carried by $\mathrm{K}^{+}$at rest will increase the membrane resistance of $\mathrm{cam}^{12} \mathrm{mu}-$ tant and presumably reduces the cooling sensitivity.
Such considerations are in line with cam $^{12}$ mutant defect in a $\mathrm{K}^{+}$current activated by hyperpolarization ( $\mathrm{R}$. Preston, personal communication).

Restoration of the cooling-sensitive response in $\mathrm{cam}^{12}$. Application of theophylline or injection of cyclic nucleotide analogs into $\mathrm{cam}^{12}$ cells caused the membrane resistance to decrease to $81 \%$ or $67 \%$, and these treatments shifted the membrane potential to hyperpolarized levels (Table I). Such changes in the $\mathrm{cam}^{12} \mathrm{mem}$ brane accompanied the restoration of the cold-sensitive current whose reversal potentials were almost the same as that of the wild-type cell (Fig. 5B). These results suggest that the decreased resting conductance of $\mathrm{cam}^{12}$ membrane is elevated by some effect of cyclic nucleotides, and the increased conductance may be a part of the cooling sensitive response.

Restoration of the cooling-sensitivity following cyclic nucleotide-injection might suggest that $\mathrm{cam}^{12}$ has a reduced level of cyclic nucleotides. In fact, it has been shown that calmodulin from Paramecium activates guanylate cyclase (25). However, the measurement of cyclic nucleotide contents shows no clear differences between wild type and cam $^{12}$ mutant cells. Therefore, the calmodulin mutation of $\mathrm{cam}^{12}$ might reduce rather the sensitivity of cyclic nucleotides-dependent reactions, e.g. a protein kinase or channel activation.

In the case of olfactory- and photo-receptor cells, cyclic nucleotides directly activate ion channels $(2,14)$, and these cyclic nucleotide-activated channels are in addition regulated by an interaction with calmodulin (1, $6,12)$. Cooling-sensitive currents in Paramecium were induced after injection of hydrolysis-resistant cyclic nucleotides and they appear dependent on calmodulin. Such a resemblance leads us to propose that the cooling-sensitive channels are directly activated by cyclic nucleotides. Following the injection of hydrolysis resistant cyclic nucleotide analogs, these concentrations are assumed to be almost constant during the cooling stimulus, while the current response is induced. This consideration rather supports the view that the coolingsensitive channels are indirectly regulated by cyclic nucleotides, e.g. through activation of cyclic nucleotidedependent protein kinases.

In conclusion, our data suggest that calmodulin and cyclic nucleotides regulate the cold-sensitive response in Paramecium mainly based on reduced $\mathrm{K}^{+}$channel activity. The reduced sensitivity of $c^{2} m^{12}$ mutant cells is probably related to the reduced number of available temperature-sensitive $\mathrm{K}^{+}$channels which are open at the resting potential. The causes for the channel activity to be transiently suppressed upon cooling remain to be determined.

Acknowledgments. We thank Dr. C. Kung and Dr. Y. Saimi (Madison, WI, USA) for providing the collection of calmodulin mu- 
tants and to Dr. T. Matsuoka (Kochi, Japan) for his encouragement. We also thank Dr. H. Machemer (Bochum, Germany) for helpful comments on the manuscript. This work was supported in part by Grant-in-Aid for Scientific Research (07680719) from the Japanese Ministry of Education, Science and Culture.

\section{REFERENCES}

1. Chen, T.-Y. and YAU, K.-W. 1994. Direct modulation by $\mathrm{Ca}^{2+}$-calmodulin of cyclic nucleotide-activated channel of rat olfactory receptor neurons. Nature, 368: 545-548.

2. Fesenko, E.E., KolesniKov, S.S., and Lyubarsky, A.L. 1985. Induction of cyclic-GMP of cationic conductance in plasma membrane of retinal rod outer segment. Nature, 313: 310-313.

3. Hennessey, T., Machemer, H., and Nelson, D.L. 1985. Injected cyclic AMP increases ciliary beat frequency in conjunction with membrane hyperpolarization. Eur. J. Cell Biol., 36: 153-156.

4. Hennessey, T. and Nelson, D.L. 1979. Thermosensory behavior in Paramecium tetraurelia: a quantitative assay and some factors that influence thermal avoidance. J. Gen. Microbiol., 112: 337-347.

5. Hennessey, T., Saimi, Y., and Kung, C. 1983. A heat-induced depolarization of Paramecium and its relationship to thermal avoidance behavior. J. Comp. Physiol. A, 153: 39-46.

6. Hsu, Y.-T. and Molday, R.S. 1993. Modulation of the cGMP-gated channel of rod photoreceptor cells by calmodulin. Nature, 361: 76-79.

7. InOUE, T. and NAKAOKA, Y. 1990. Cold-sensitive responses in the Paramecium membrane. Cell Struct. Funct., 15: 107-112.

8. Kerboeuf, D., Le Berre, A., and Dedieu, J.-C. 1993. Calmodulin is essential for assembling links necessary for exocytotic membrane fusion in Paramecium. EMBO J., 12: 3385-3390.

9. Kink, J.A., Maley, M.E., Preston, R.R., Ling, K.-Y., Wallen-Friedman, A., Saimi, Y., and Kung, C. 1990. Mutations in Paramecium calmodulin indicate functional differences between the $\mathrm{C}$-terminal and $\mathrm{N}$-terminal lobes in vivo. Cell, 62: $165-174$.

10. Kung, C., Preston, R.R., Maley, M.E., Ling, K.-Y., Kanabrocki, J.A., Seavey, B.R., and SaImi, Y. 1992. In vivo Paramecium mutants show that calmodulin orchestrates membrane responses to stimuli. Cell Calcium, 13: 413-425.

11. Ling, K.-Y., Marley, M.E., Preston, R.R., Saimi, Y., and KunG, C. 1994. New non-lethal calmodulin mutations in Paramecium. Eur. J. Biochem., 22: 433-439.
12. Liu, M., Chen, T.-Y., Ahamed, B., Li, J., and YaU, K.-W. 1994. Calcium-calmodulin modulation of the olfactory cyclic nucleotide-gated cation channel. Science, 266: 1348-1354.

13. Machemer, H. 1988. Electrophysiology. In Paramecium (ed. Gortz, H.D.) Springer, Berlin Heidelberg, pp.185-215.

14. Nakamura, T. and Gold, G.H. 1987. A cyclic nucleotidegated conductance in olfactory receptor cilia. Nature, 325: 442444.

15. NAKAOKA, Y. and IwATSUKI, K. 1992. Hyperpolarization-activated inward current associated with the frequency increase in ciliary beating of Paramecium. J. Comp. Physiol. A, 170: 723727.

16. NakaOKa, Y., Kurotani, T., and IтoH, H. 1987. Ionic mechanism of thermoreception in Paramecium. J. Exp. Biol., 127: 95103.

17. NAKAOKA, Y. and MAChEMER, H. 1990. Effects of cyclic nucleotides and intracellular $\mathrm{Ca}^{2+}$ on voltage-activated ciliary beating in Paramecium. J. Comp. Physiol. A, 166: 401-406.

18. NAKaOKa, Y. and Oosawa, F. 1977. Temperature-sensitive behavior of Paramecium caudatum. J. Protozool., 24: 575-580.

19. Oertel, D., Schein, S.J., and Kung, C. 1978. A potassium conductance activated by hyperpolarization in Paramecium. $J$. Membr. Biol., 43: 169-185.

20. OKa, T., NaKaOKa, T., and Oosawa, F. 1986. Changes in membrane potential during adaptation to external potassium ions in Paramecium caudatum. J. Exp. Biol., 126: 111-117.

21. Oosawa, Y. and Yamagishi, S. 1989. Rat brain glutamate receptors activate chloride channels in Xenopus oocyte coupled by inositol triphosphate and $\mathrm{Ca}^{2+}$. J. Physiol., 408: 223-232.

22. SAIMI, Y. and KUNG, C. 1994 . Ion channel regulation by calmodulin binding. FEBS Lett., 350: 155-158.

23. SAIMI, Y. and LING, K.-Y. 1990. Calmodulin activation of calcium-dependent sodium channels in excised membrane patches of Paramecium. Science, 249: 1441-1444.

24. Saimi, Y. and Ling, K.-Y. 1995. Paramecium $\mathrm{Na}^{+}$channels activated by $\mathrm{Ca}^{2+}$-calmodulin: Calmodulin is the $\mathrm{Ca}^{2+}$ sensor in the channel gating mechanism. J. Membr. Biol., 414: 257-265.

25. Schultz, J.E., Pohl, T., and KlumpP, S. 1987. Voltage-gated calcium entry into Paramecium linked to intraciliary increase of cyclic GMP. Nature, 322: 271-273.

26. TominaGa, T. and NaIToH, Y. 1992. Membrane potential response to thermal stimulation and the control of thermoaccumulation in Paramecium caudatum. J. Exp. Biol., 164: 39-53.

(Received for publication, April 14, 1997

and in revised form, June 3, 1997) 